\title{
Food, Farm and Fuel: An Inequitable Supply Chain
}

\section{INTRODUCTION}

Within days of war breaking out the country faced a torrent of problems including "extraordinary chaos in the Food Market". At Napsbury Asylum, the grain and flour supplier backed out of his contract because imports failed to arrive, and Nestlé stopped deliveries because the government required its stocks. The standard of bread fell because much yeast was imported and consequently unobtainable. Fish was suddenly unavailable because "as the Steamers return they are being laid up pending events." "Foods such as meat, and other items considered healthy by early twentieth century nutritional scientists, were prioritised for the soldiers. ${ }^{2}$ The large contracts for food required by the asylums became particularly vulnerable. There were many challenges in addition to obtaining supplies, including coping with a capped budget, concerns about cooking to avoid exhausting limited fuel supplies, and resident staff voicing discontent about the food provided for them. Limited understanding of nutrition, and patterns of inequitable food distribution within the asylums according to rank rather than health need, also contributed to an unsatisfactory diet for patients.

In order to contextualise and explain the situation in the asylums, this chapter begins by outlining the national position with regard to food, then, in the context of nutritional understanding, explores asylum supply and demand issues, patients' communal meals, and food distribution.

C. Hilton, Civilian Lunatic Asylums During the First World War, Mental Health in Historical Perspective, https://doi.org/10.1007/978-3-030-54871-1_5 
Some of the challenges faced by asylum farms, and the use of fuel, another precious commodity, are also discussed.

\section{The National Food Context}

Until the war, Britain imported about 60 per cent of its food. As in the lyrics of Rule, Britannia!, "Britannia rule the waves", 3 it could not conceive of any way in which its sea routes could be disrupted, neither had it envisaged the possibility of a prolonged conflict nor interruption of trade by submarines. ${ }^{4}$ The country produced one fifth of its wheat, two fifths of its butter and cheese, three-fifths of its meat and bacon, and none of its sugar. Only in respect of fish, milk and potatoes was it self-sufficient.

A few days after war was declared, the government passed the Defence of the Realm Act (DORA) which gave it authority to control many aspects of civilian life, including food supplies. This system of national government-led welfare was new: earlier, providing and controlling resources would have been in the hands of voluntary bodies. ${ }^{5}$ It was a change with potential to influence future welfare policy. At the same time, Walter Runciman was appointed president of the Board of Trade. Consistent with Runciman's free-trade principles and the Liberal government's general philosophy, his lack of intervention inhibited the development of a coherent food policy. ${ }^{6}$ Nevertheless, behind the scenes, the government amassed emergency supplies of essential food stuffs such as wheat, ${ }^{7}$ and took control of the sugar supply, two-thirds of which was usually imported from Austria-Hungary. ${ }^{8}$ Inclement weather and the reduced availability of ammonia, which was used to produce both fertilisers and explosives, affected home-grown crops. ${ }^{9}$ Despite threats to the food supply, in the view of William Beveridge (later, draftsman of the welfare state), until late 1916 "there was no general food problem in Britain". ${ }^{10}$

Administrative errors caused local shortages, such as sugar supplies to retailers being based on pre-war sales patterns, due to failing to take into account large scale civilian population movement for munitions and other work. ${ }^{11}$ War inflation, higher costs of freight, and panic buying, all contributed to higher food prices and caused public discontent, but according to an analysis by Gerd Hardach, most food stuffs remained within reach of poorer people. ${ }^{12}$ An independent committee, appointed by the government, which investigated wartime life for working class people found that dietary energy levels for community dwellers were 
generally maintained, although intakes of some key nutrients deteriorated. ${ }^{13}$ For some households, with a father in the forces and a mother with young children relying on the meagre "separation allowance", life was a struggle. ${ }^{14}$ Some oral histories recalled experiences of persistent hunger among working class children, and families who attributed deaths of younger siblings to malnutrition. ${ }^{15}$ Two years into the war, food prices had almost doubled. ${ }^{16}$ For many in the community, high rates of employment and some increase in salary partly compensated for the steep price rises. ${ }^{17}$ An asylum, of course, was an employer, so was responsible for paying the "war bonus" increases to its non-resident staff to cover their higher daily living costs. Within a framework of a budget capped by the Lunacy Act 1890 which stipulated a maximum outlay of $14 \mathrm{~s}$ (shillings, 70p) per patient per week to cover all asylum running expenses, including staff salaries, ${ }^{18}$ the outcome was less money to spend on food for patients and staff who were resident in the asylum.

The government aimed to avoid compulsory rationing and invited the public to participate in voluntary dietary restrictions, much as it initially encouraged voluntary military recruitment rather than introduce conscription. ${ }^{19}$ However, from 1916, German "U-boat" submarines specifically targeted merchant ships with great loss of life and cargo, and food supplies were again in crisis. The government feared that if families sent letters to soldiers describing their daily problems, or if soldiers experienced the difficulties when home on leave, this would undermine military morale. $^{20}$ To deal with this, to "maintain war production and prevent unrest at home" the government established a Ministry of Food. ${ }^{21}$ It was headed by a "Food Controller", rather than a Minister, and was empowered to regulate supply and consumption and to take steps to encourage food production. ${ }^{22}$ Beveridge was appointed Permanent Secretary to the Ministry. $^{23}$

The first Food Controller, Lord Devonport, a grocery stores magnate, continued to promote voluntary dietary adaptations, aiming to reduce the consumption of foods in short supply and to avoid waste when cooking. Some commentators have proposed that his laissez faire approach was founded on a financial conflict of interest. ${ }^{24}$ The Ministry of Food proposed dietary guidelines in February 1917 (Table 5.1) which applied to domestic environments where each household member was assumed to have different nutritional requirements: food needs of a labourer and young child in the same household would probably balance out so that neither went hungry. Some households could supplement diets with 
Table 5.1 Weekly food allowances under various rationing schemes

\begin{tabular}{|c|c|c|c|}
\hline $\begin{array}{l}\text { Recommended } \\
\text { intake, general } \\
\text { population, Feb. } \\
1917\end{array}$ & $\begin{array}{l}\text { Compulsory rationing, } \\
\text { general population, Nov. } \\
1917\end{array}$ & $\begin{array}{l}\text { LCC asylum } \\
\text { patients, Nov. } \\
1917\end{array}$ & $\begin{array}{l}\text { Compulsory rationing, } \\
\text { general population, early } \\
1918\end{array}$ \\
\hline Sugar $12 \mathrm{oz}$ & $\begin{array}{l}\text { Sugar } 8 \mathrm{oz} \\
\text { Fats } 10 \mathrm{oz}\end{array}$ & $\begin{array}{l}\text { Sugar } 71 / 4 \mathrm{oz} \\
\text { Fats } 71 / 4 \mathrm{OZ}\end{array}$ & $\begin{array}{l}\text { Sugar (adult or child) } \\
8 \mathrm{oz} \\
\text { Fats (adult or child) } 8 \mathrm{oz}\end{array}$ \\
\hline Bread $4 \mathrm{lb}$ & $\begin{array}{l}\text { Bread } \\
\text { (age/gender/occupation) } \\
3^{1 / 2} \mathrm{lb} \\
\text { ("sedentary/unoccupied } \\
\text { woman")-8 lb }\end{array}$ & $\begin{array}{l}\text { Bread } \\
\text { (average) } \\
43 / 4 \mathrm{lb}\end{array}$ & $\begin{array}{l}\text { Bread } \\
\text { (age/gender/occupation) } \\
3-7 \mathrm{lb}\end{array}$ \\
\hline Meat $2 \frac{1}{2} \mathrm{lb}$ & Meat $2 \mathrm{lb}$ & Meat $13 / 4 \mathrm{lb}$ & $\begin{array}{l}\text { Meat } 2 \mathrm{lb} \\
\text { Use carefully: Cheese, } \\
\text { milk, oatmeal, rice, tea, } \\
\text { jam } \\
\text { Unrestricted: Potatoes, } \\
\text { fruit, vegetables, eggs, } \\
\text { fish }\end{array}$ \\
\hline
\end{tabular}

Sources LCC LCC/MIN/00582 Meeting, 27 February 1917, 434 LMA; LCC LCC/MIN/00583, 27 November 1917, 175-76 LMA; BBC, "World War One: What Shops Were on the High Street? Rationing," http://www.bbc.co.uk/schools/0/wwl/2523537l

home-grown produce, and a cook "in an ordinary household" could make many "small economies". Regarding institutions, those which solely housed adults lost the benefits of juggling supplies on the basis of individual nutritional requirements across the lifespan, and a handful of cooks feeding 2000 resident patients and staff seven days a week were unlikely to be able to replicate economies made in a household kitchen.

The second Food Controller, Lord Rhondda, an industrialist and politician, introduced compulsory rationing at the end of 1917, beginning with butter, margarine and sugar (Table 5.1). ${ }^{25}$ Food queues in London, which had reached one and a half million people a week, diminished with compulsory rationing. ${ }^{26}$ Rationing was intended to provide a state determined allocation of food to all, with flexibility for age, health, religious and other needs. ${ }^{27}$ The entire country, including King George and Queen Mary had ration books, with their allowances calculated on the same ration scale as their subjects. ${ }^{28}$ Everyone had their rations derived from a scale roughly tailored to their needs, but this would only be achieved if those rations were distributed equitably. In asylums, the 
hierarchical culture, difficulties in economising in ways which might be possible in a household setting, together with escalating food prices and other higher expenses within a limited budget, contributed to a precarious food situation.

\section{Asylum Diets: Supply and Demand}

The asylums contended with unpredictable food supplies pre-war, ${ }^{29}$ in contrast to the relatively stable situation for the rest of the country. They procured enormous quantities, had little access to refrigeration, and kept only minimal stocks. Suppliers knew this, and its implications, that asylums had to accept deliveries even if substandard. ${ }^{30}$ Food might be "stale and unfit for consumption" at the time of delivery, ${ }^{31}$ and even when fit, it was often best cooked the same day to prevent deterioration, serving it the following day. ${ }^{32}$ Some asylums spent as little as $4 \mathrm{~s}(20 \mathrm{p})$ per patient per week on food, a sum independent of the amount of food provided by the asylum farm. ${ }^{33}$

Benjamin Seebohm Rowntree's study of poverty in fin de siècle York provides useful dietary comparators for the asylums in 1914. These comparisons are possible because there was almost no inflation or change in eating habits during this period. Rowntree found weekly food expenditure to be approximately $3 \mathrm{~s} 6 \mathrm{~d}\left(18^{1 / 2} \mathrm{p}\right)$ per adult male in households of the lowest wage earners and $3 \mathrm{~s} 91 / 2 \mathrm{~d}(19 \mathrm{p})$ in the workhouse. He incorporated into his analysis the most up-to-date estimates of the nutritional value of these people's diets. Analyses were generally limited to calorie and protein content, standardised to the bodily needs of a person at rest in a warm room. ${ }^{34}$ Not only was the situation of being at rest in a warm room likely to be unusual for the poorest of the working classes in York, but even when based on these calculations, their diet was deficient in calories and protein by around 25 per cent. ${ }^{35}$ Similar deficiencies were likely for patients living in asylums with poor quality clothes and inadequate heating and with high levels of bodily energy usage due to restlessness, co-existing physical illness, much manual work and having long distances to walk such as to the lavatories and dining hall.

In contrast to Rowntree's analysis, Diane Carpenter, in her study of two Hampshire asylums pre-war, concluded that asylum food was better than in workhouses and often better balanced than that available to most poor people. ${ }^{36}$ Her conclusions suggest variation between asylums, but 
for those functioning at Rowntree's level, diet would have been insufficient to promote health and wellbeing, or to help the recovery of patients who required more calories due to their mental and physical disorders. Keeping to the Lunacy Act's budget of 14 s per week per patient, was a constant challenge for the asylums. Barely feasible in the low inflation period pre-1914, the London County Council (LCC) found it unachievable during the war. ${ }^{37}$ The financial target contributed to a culture of minimising expenditure, accompanied by the temptation to divert savings made by cutting food costs to benefit other, more outwardly visible, asylum needs. The 14s compared unrealistically with the average weekly general hospital cost of $28 \mathrm{~s}$ per patient, or $45 \mathrm{~s}$ in one Red Cross Hospital, even allowing for the different disorders being treated. ${ }^{38}$ With wartime inflation, expenditure on asylum food did not increase: there were other priorities, including paying the staff to keep the asylums functioning. Psychiatrist William Stoddart cautioned in 1916: "It is false economy on the part of the authorities of many county asylums to keep down the maintenance rate by economising food." 39 His message fell on deaf ears.

In contrast to the situation for the general public, wartime food rationing began early for people in the asylums. We hear little from patients about the food, although one patient later alleged: "My wife brought in food. Else I should have been starved", 40 and another volunteered for kitchen work, and "got better food because I really stole it". 41 We hear more from the resident staff who were also subject to early rationing. With compulsory deductions from their already low wages for board and lodging, they had little option but to eat the food provided. They resented the dietary restrictions and food monotony which those outside did not have to endure. ${ }^{42}$ At Hanwell, one nurse left, alleging that she was being starved. Others complained about rancid margarine, poor quality bacon, only one potato at dinner, small meat allowances and bread inferior to what was on sale outside. ${ }^{43}$ The LCC attempted to improve staff food, ${ }^{44}$ occasional seeking expert external advice to try to make it more palatable. ${ }^{45}$ It justified allocating more and better quality food to staff to keep them well enough to care for the patients, to alleviate employee discontent, and to prevent them taking the patients' food. ${ }^{46}$ However, since food supplies within the asylum were pooled, ${ }^{47}$ a strategy of providing more for staff, automatically diminished quantities available for patients. One asylum management "visiting" committee (VC), pleased with its ingenuity in issuing bread directly to wards, reported that it reduced expenditure and waste and "every patient or member of the 
staff has what he requires". Other evidence throws this open to dispute, because only staff held keys to the store cupboards, and when they were hungry, they took the patients' bread. ${ }^{48}$ Visiting committee members lived in the un-rationed community outside the asylum, and sometimes appeared to lack a detailed appreciation of asylum life. ${ }^{49}$

The asylum economy and the external supply chain were major considerations throughout the war for the VCs and the national asylums' Board of Control ("the Board"). Regarding the main dietary staple of bread, shortage of wheat flour necessitated substitutions of un-rationed ingredients such as barley, oatmeal, rice, sago, tapioca, maize or potatoes. ${ }^{50}$ Twenty pounds $(20 \mathrm{lb}, 9 \mathrm{~kg})$ of potatoes could be mixed with 1 sack $(280 \mathrm{lb}, 127 \mathrm{~kg})$ of flour. ${ }^{51}$ Kitchen staff disliked the additional labour it required without a potato mashing machine. ${ }^{52}$ Bread made with potatoes also tasted different and was unpopular with consumers. ${ }^{53}$ Bran or wheatgerm could be added, a financially sound alternative, ${ }^{54}$ but not always acceptable in a culinary culture which considered white bread best and wholemeal inferior. ${ }^{55}$ The Board welcomed the news of a glut of cheap pickled and smoked herring on the market. It distributed to the asylums the Ministry of Food's recipe guide: herrings could be boiled, steamed, fried, grilled, baked, poached, stuffed, soused or curried, served with lemon sauce, in a pie or salad, or potted in vinegar. ${ }^{56}$ The recipes were generally for household quantities, and whether they would translate effectively into mass-catering was uncertain.

\section{Asylum Diets and Nutritional Understanding}

The VCs' track record of prioritising lowest possible expenditure, plus little grasp of emerging nutritional science, ${ }^{57}$ was a potentially disastrous combination. Although the Board made recommendations in line with nutritional knowledge, for example suggesting high protein substitutes such as cheese, beans, lentils or peas when meat was in short supply, VCs, with one eye on the books, proposed puddings, fruit pies and rice, cheaper but hardly equivalent nutritionally. 58 Tenna Jensen's study of nutritional science and early twentieth-century institutional diets (in Denmark) indicated that, in spite of societal awareness of nutrition, incorporating that knowledge into institutional diets was far from universal. Instead, institutional diets focussed more on the need for food to be filling. ${ }^{59}$ Knowledge could have a time lag of several years before filtering 
through to institutional implementation, with the result that war time asylum diets tended to follow obsolete guidelines.

Regarding vitamins, discovered around 1912, their mode of action was still "immature views and guesses" 60 and their presence in food unquantifiable, ${ }^{61}$ but the medical profession acknowledged their "astonishing properties" which could "profoundly affect" physical and mental health. ${ }^{62}$ Regarding vitamin $\mathrm{C}$ just before the war, patients at Colney Hatch received " $1 / 2 \mathrm{lb}$ fruit weekly per head in the summer" $(0.25 \mathrm{~kg}) .^{63}$ When combined with plenty of potatoes and other root vegetables, vitamin $\mathrm{C}$ intake was probably adequate: none of the medical records examined in the course of researching this book referred to scurvy. Although more fruit may not have been considered essential to the diet, sugar, because of its calorie content was regarded as a vital nutrient. Prewar, the nine LCC lunatic asylums consumed 10 tons of sugar between them each week, about $1 \mathrm{lb}(0.5 \mathrm{~kg})$ per person. ${ }^{64}$ It was standard asylum practice to sweeten hot drinks. Typically, a gallon size pot contained $1 \mathrm{oz}$ $(28 \mathrm{~g})$ tea, $4 \mathrm{oz}$ sugar and $12 \mathrm{oz}$ milk, with similar proportions for a gallon of coffee or cocoa. ${ }^{65}$ In 1916, the LCC asked medical superintendents to suggest "dietary substitutes...to take the place of necessary food for patients caused by the great reduction of sugar allowance". ${ }^{66} \mathrm{It}$ also asked the Royal Commission on the Sugar Supply for more sugar for asylums "having regard to the fact that the issues of sugar at the asylums have already been reduced to the lowest limit which is believed to be compatible with good health". Nevertheless, the LCC oversaw inequitable distribution of sugar: $1 / 2 \mathrm{lb}$ per patient and $\mathrm{l} \mathrm{lb}$ per resident member of staff per week in $1916,{ }^{67}$ pointing to the nutrition of staff being prioritised over that of patients.

Nutritional understanding by VCs also contributed to how they interpreted government dietary recommendations which were often formulated in terms of maximum amounts which were not to be exceeded. ${ }^{68}$ The general understanding was that if individuals did not need the maximum, it was fine if they ate less of their own volition. ${ }^{69}$ Maximum quantities, however, in the asylums, were interpreted on behalf of the patients who had little individual choice or agency. Claybury's VC wanted to provide patients with "less than the maximum scale" of bread, cake, potatoes, meat, pudding, fish, coffee, tea, sugar, margarine, flour, dripping, jam and cheese. ${ }^{70}$ Two weeks later, at the VC's next meeting, medical superintendent Robert Armstrong-Jones argued against their proposal: "The standards in use are the result of many years of thought 
and experience and a lowering of standard does not necessarily lead to a saving", echoing Stoddart's message. ${ }^{71}$ If any reductions were made, Armstrong-Jones continued, they should be on the basis of careful study of the entire food contract, not just chosen arbitrarily or to make financial savings. ${ }^{72}$ Armstrong-Jones was aware of his VC's tendency to make decisions based on finance rather than on patients' wellbeing. Claybury did not introduce this across-the-board food reduction, but less dramatic dietary reductions followed. By contrast, interventions to increase patients' food intake were miniscule and half-hearted: when a medical officer at Hanwell suggested that each patient should receive an extra pound of potatoes a week, the VC reduced it to half-a-pound. ${ }^{73}$ Asylums neglected to provide food according to the patient's needs. The simple and recommended act of weighing asylum patients regularly to detect malnutrition or disease was implemented inconsistently, suggesting a lack of concern or interest. ${ }^{74}$ Patient Mary Riggall reported in her memoir of asylum life that her weight declined from 9 to 6 stones (57-38 kg) during her 18 -month admission, ${ }^{75}$ supporting the notion that balancing diet with energy expenditure, whether due to illness or occupation, was ignored.

The emphasis on balancing-the-books rather than patients' wellbeing fitted with the practice of allocating additional food to "working" patients, that is, to those whose work the asylum considered economically useful. ${ }^{76}$ In contrast, a patient undertaking physical activities for their therapeutic benefit alone did not receive extra, regardless of energy expenditure. This valued a patients' economic contribution above stated ideals of considering activities as intrinsically therapeutic and important to wellbeing and self-esteem, regardless of whether they benefited the institution financially. When one considers the meagre lunch provided to female patients employed on Hanwell's farm-3 oz $(90 \mathrm{~g})$ bread with either $1 / 2$ oz cheese or $1 / 2$ oz treacle depending on availability-probably under 300 calories, ${ }^{77}$ it is hard to identify what might have been considered "additional".

In 1917, the medical superintendents discussed weight loss and high asylum death rates side by side and drew the Board's attention to the effects of food restrictions. ${ }^{78}$ At Hanwell acting medical superintendent Alfred Daniel informed the VC that the rising death rate was "partly due to shortage of food", noting the introduction of dry bread for supper instead of bread and dripping, ${ }^{79}$ and that "pudding" had only one-fifth 
the calories of the same item produced earlier in the war. Food preparation advice to asylums included to boil food rather than roasting or frying it, to conform with government demands to economise on gas consumption, ${ }^{80}$ but this reduced both calorie and nutritional content. In July 1918, with rising death rates at Hanwell-26 people in one monthDaniel sought advice from the local authority medical officer of health. ${ }^{81}$ The same month, the Board reiterated that all patients should be weighed every 3 months "If not already done as a matter of routine" to monitor dietary adequacy, and that patients and resident staff should be allocated food to provide 2600 calories a day. ${ }^{82}$ However, Hanwell did not even provide that amount to its shell-shocked patients, those deemed worthy of the best care. They received 2200 calories daily; the VC minutes did not state what was provided for the civilian patients. Diets at Hanwell for the shell shocked patients compared unfavourably to the 3350 calories daily provided at the Maudsley Military Hospital, dedicated entirely to soldier's mental health. ${ }^{83}$ Rations in asylums were also inequitable when compared to those provided in the war hospitals which were created by vacating asylums. When Napsbury became a war hospital, about eighty male asylum patients and some asylum staff remained on site to tend the farm and gardens. The Board's circulated guidance on maximum dietary allowances only applied to these patients and staff. It was "not intended to apply to Military patients or any of the staff" looking after them. ${ }^{84}$ Many of the soldier-patients recovering from injuries would have needed more calories than physically healthy individuals, but farm work was no less strenuous and demanding of an adequate diet than nursing the soldier-patients. The Board's action was nonsensical based on recognised nutritional criteria. Apart from desiring to minimise financial expenditure, or wanting to comply with Whitehall's directives, it is hard to see the rationale or humanity of making this distinction.

When the distinguished psychiatrist and researcher Frederick Mott, probably the most knowledgeable authority about the health of asylum patients in England, communicated his concerns about food restrictions directly to the Board, it minuted its intention to enquire from asylums to what extent there were grounds for his anxiety. ${ }^{85}$ No answers appear in subsequent minutes. The asylum leadership sometimes tried to avoid discussing awkward issues, including about diet, and evaded questions when asked directly. The Cobb Inquiry about asylum standards demonstrated this: when the panel asked the chairman of one VC: "You must have been badly off during the war for potatoes?" he replied: "We gave 
them an excellent quality of margarine" ${ }^{86}$ It was hardly an adequate response.

The Board's preoccupation with doing as the Ministry of Food asked and maintaining its reputation as a compliant authority, may have contributed to its lack of action to ensure adequate food for patients. Throughout the war, its rigid advice to asylums contrasted with the government's strategy of encouraging voluntary initiative before compulsion. The Board emphasised compliance with dietary restrictions, even when uncertain whether the rules were applicable to institutions entirely for adults. ${ }^{87}$ In contrast to the Board's inactivity, the prison authorities interpreted the Ministry's recommendations less stringently. They negotiated with the Ministry, so that in their institutions with all adult prisoners, bread was provided at the standard rate plus $2 \mathrm{lb}(\mathrm{l} \mathrm{kg})$, giving each person an extra 2000 calories a week. Although directly comparing asylum and prison dietary regimes is complex, because different categories of prisoner received different diets, overall, calorie intake of prisoners exceeded that of patients in asylums. ${ }^{88}$ Notably, prisoners did not suffer the high rate of infectious diseases, such as tuberculosis, compared to asylum patients. In addition, unlike most prisoners who had a release date, asylum patients could be detained indefinitely, so for many of them, poor nutrition could be of prolonged and indeterminate duration. The Board's minutes available at the National Archives provide no evidence that it knew about, asked about, or acted on, the prison diet experience.

\section{Communal Eating for Patients and Staff}

"The healthfulness of a variety of food is allowed by the best authorities; but beyond its healthfulness, its desirability is beyond doubt" wrote Charles Mercier in his book on asylum management. ${ }^{89}$ Not only nutrition, but also palatability and presentation of food were important in Mercier's eyes. For patients, the food which arrived on their plates could be unappetising. Mott regarded oatmeal porridge with treacle four days a week for tea at Hanwell as particularly uninviting. ${ }^{90}$ Too often food was poor quality and could be "abominably cooked".91

On the first day of a Board inspection at one asylum in November 1914 , the stew was unpopular, but the following day there was "roast beef and mutton with bread and two vegetables, the enjoyment of which was obvious". ${ }^{92}$ Two meats in one meal was rare on asylum menus. It is likely that, having made an unfavourable initial impression, the asylum then laid 
on a culinary treat. Food often improved on Board inspection days or when the VC made its rounds. Staff at Claybury described "Committeeday soup", which was far better than the usual "flour with the water", and vegetables which were "stalks, dead leaves and slugs" and "When one man picks up a caterpillar with his fork the others are done."93 In one asylum, the main meal of the day consisted of rhubarb pudding with bread and cheese: the Board reported that the "change from a meat diet on one day in the week is looked upon with favour by the patients". ${ }^{94}$ This may have been the Board's genuine understanding, but at a time when meat or fish was an expected constituent of a main meal, patients may have expressed their appreciation as they felt obliged to do so. Unlike when the inspectors received criticism from patients, they warmly accepted their praise, without attributing it to mental disorder. If the inspectors observed patients and staff enjoying a good meal they were unlikely to take foodrelated complaints seriously. They appeared unaware that a display might be created for their benefit.

Inspectors also evaluated routines of communal eating. Meals were often rushed: "Toothless old men had sometimes to wrestle with chunks of fat or gristle; they swallowed their food somehow or other, but had no time to masticate it properly". 95 Stoddart criticised nurses who rushed patients with their food due to their own working demands. He used military metaphor: "just as the velocity of a fleet is that of its slowest vessel, the duration of a meal must be that of the slowest eater." 96 Some patients who ate with great haste were labelled as greedy, but some were probably extremely hungry or worried that other patients would snatch their food. ${ }^{97}$ So-called greediness also occurred in some brain diseases, such as general paralysis of the insane (GPI, syphilis), which could predispose patients to disinhibited table manners and to bolt their food. GPI could also impair swallowing which could result in choking. ${ }^{98}$ A soft diet eaten with a teaspoon could reduce that risk, but if the need was not recognised, a patient could choke to death. That happened to Louis L, a prisoner of war at Colney Hatch, a horrible ending of life for the patient, and very disturbing to those around. ${ }^{99}$

The Board noted other aspects of mealtimes, which they thought could help make them as pleasant as possible. It was keen on communal recitation or singing of grace when patients were all seated, as a prelude to an orderly meal. ${ }^{100}$ Inspectors advised one asylum that chipped and broken mugs should be replaced "at once", but did not state whether this was for safety, hygiene, or aesthetics. ${ }^{101}$ They praised another where "crockery 
plates and glass tumblers are gradually being substituted for the enamelled iron plates and mugs". ${ }^{102}$ Some patients must have been considered sufficiently trustworthy for the change, but it is unclear for how long others continued to use the enamelled implements, or whether inspection routines influenced the changeover. Every meal, whether on a ward, in the dining hall, or in the staff mess room, concluded with the routine of counting in the cutlery, for fear it could be used to injure self or others. ${ }^{103}$

\section{Food Distribution in the Asylums}

The bureaucratic web embedded in the asylum's hierarchical culture, determined food distribution, and the quality and quantity of food served. It often failed to produce an equitable share for all. The medical officers, matron and assistant matrons usually received the best, and patients the worst. ${ }^{104}$ Inequalities were enshrined in official guidance, such as the LCC's instruction: "Instead of Officers' Fish at $7 \mathrm{~d}$. and patients' at $2 \frac{1}{1} 2 \mathrm{~d}$., take a contract for mixed fish and pick out the best for the officers", 105 or their recommended Christmas spending of $6 \mathrm{~d}$ for each patient and $2 \mathrm{~s} 3 \mathrm{~d}$ for each resident member of staff. ${ }^{106}$ Dietary plans for patients and lower tiers of staff included serving them preserved beef, when the same asylums aimed to provide senior staff with "joints of English killed mutton". 107 When charge nurses, from the middle ranks of Claybury's work force, complained that the kitchen staff reserved the best flour for bread for the most senior staff, the VC ended the practice with haste. ${ }^{108}$ Neither the reason for the VC's rapid response nor the motivation behind the kitchen staff action were recorded, although obsequiousness to seniors was replayed throughout the asylum system in multiple ways. Montagu Lomax recalled that during the war at Prestwich Asylum, cream for medical officers was provided by skimming the patients' milk. ${ }^{109}$ Also, according to Lomax (with his italics), the following contributed to impairing patients' vitality ${ }^{110}$ :

unjust and unequal distribution of the sufficient and available food, the combination of official lavishness and waste, the incompetent management, the careless and unscientific cooking,...the neglect of opportunities for increasing the supply of asylum-grown vegetables-in a word, all the evils of the administrative system. ${ }^{111}$ 
As well as externally sourced food, produce home-grown on the asylum farm was also distributed unevenly. At Claybury, when $400 \mathrm{lb}$ of strawberries were harvested just over half was shared between the 2000 patients, and the rest between 200 staff. $^{112}$ When VC minutes mentioned that their farm provided staff with fruit for desert or lettuce with their tea, they failed to indicate any similar provision for patients. ${ }^{113}$ In view of asylums' lack of attention to vitamins in food, distribution was probably based on a desire to add interest to the diet. There could be little justification, however, for the inequity demonstrated at Colney Hatch, where, in stark contrast to the low allowance of fresh fruit for patients, the most senior asylum personnel were permitted to purchase up to $7 \mathrm{lbs}$ of fruit a week and unlimited quantities of milk and vegetables. ${ }^{114}$ There were other inequitable purchases: in spring 1915, Armstrong-Jones purchased goods to the value of $£ 25$ from Claybury's stores, three times that of the next highest spender in the same period. The VC scrutinised the list of staff spending without further comment. ${ }^{115}$ Armstrong-Jones might have had a legitimate reason for doing this, or he might have exploited his privilege of rank. Backdoor shopping by higher social classes occurred in the community where it caused fury among those less privileged. ${ }^{116}$ When it occurred in the asylums, the patients would have suffered most as a result. Even if patients knew about it, if they complained, there is little evidence that their voices were heard.

\section{AsYlum FARMS}

Asylum farms were integral to the institutions. They produced milk, eggs, fruit and vegetables to supplement asylum diets, provided employment for many patients and generated income from sales to staff, to other asylums and on the open market. ${ }^{117}$ Shortly before the war, some asylums produced large quantities of food. In one fortnight in 1913, Colney Hatch farm produced 2300 eggs and farrowed 28 pigs, and slaughtered 20 pigs and 2 cows for use in the asylum. Later that year it harvested $22,000 \mathrm{lb}$ onions, most of which were used in asylum food. ${ }^{118}$ Crop success stories are harder to find during the war. In autumn 1914, Hanwell's farm had poor vegetable and root crops due to drought. The following month blight destroyed all the Brussels sprouts. In discussion with the farm bailiff, in early 1915 the VC approved the proposal to grow wheat under the special circumstance of the war. This was controversial in an urban area where house sparrows were known to "exact a very heavy 
toll" on grain crops. Inexplicably, it was "left to the medical superintendent to decide as to the acreage to be sown". ${ }^{119}$ Whether he had the agricultural expertise to take this decision, or if it was delegated to him on the basis of his overall leadership of the asylum, was not stated.

The weather over successive war years was deleterious to farming. At Hanwell, drought affected the farm early in 1915, upsetting sewing and transplanting. ${ }^{120}$ The protracted and harsh winter of 1915-1916 particularly affected early crops and poultry, with only 3000 eggs laid compared to 5000 in the same period the previous year. ${ }^{121}$ Heavy rain and hail after sowing late wheat in 1917 battered down the soil which became "so hard that the young shoots could not break through". ${ }^{22}$ In 1918, incessant rain followed the worst drought for 12 years. ${ }^{123}$ Some senior farm staff, such as the bailiff, ploughman and head cowman, were exempt from military service, ${ }^{124}$ but many others enlisted or moved into munitions work. Adverse weather conditions, reduced availability of synthetic fertilisers, bureaucratic asylum management, and less experienced farm staff, ${ }^{125}$ probably all contributed to lower yield.

Land usually used for recreation in asylums (Fig. 5.1) was ploughed

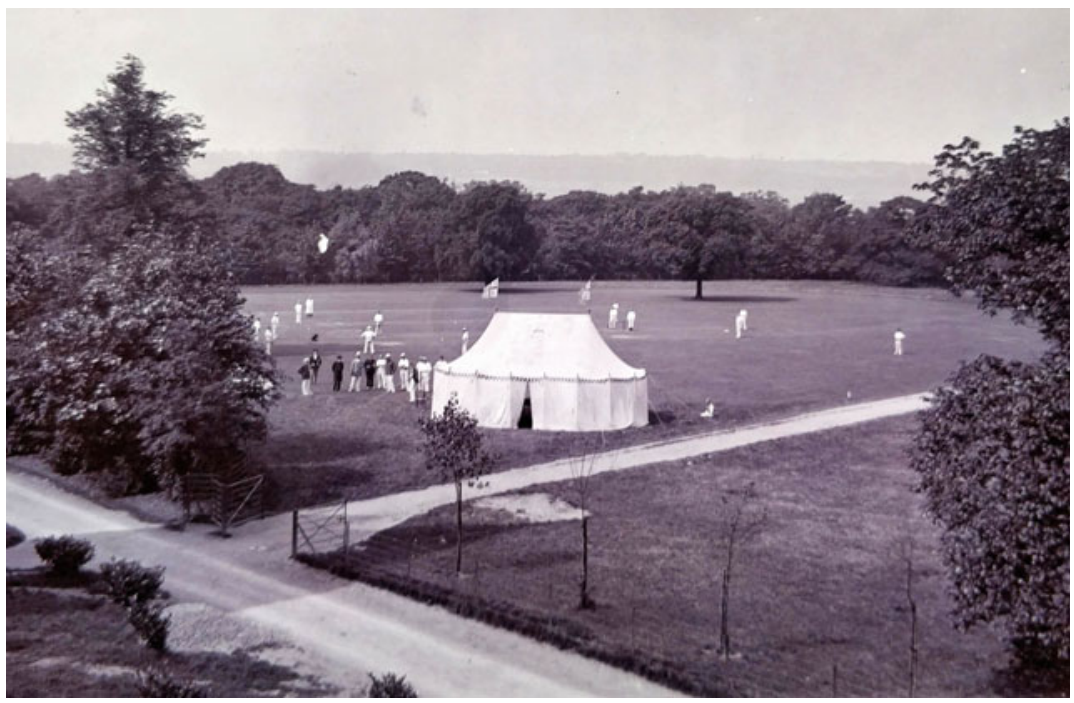

Fig. 5.1 Cricket pitch at Claybury, before 1917 (Armstrong-Jones collection, Royal College of Psychiatrists' Archives) 
and cultivated, ${ }^{126}$ as elsewhere, such as in the nine LCC parks which together produced $3 \frac{1}{2}$ tons of tomatoes in 1917 and the vegetable patches which replaced flowerbeds at Buckingham Palace. ${ }^{127}$ Occasionally farms undertook new projects, such as bee keeping at Colney Hatch. Shortages of materials and staff affected the farms. Hanwell's VC declined the chance to purchase a motorised tractor, which could have compensated for fewer farm staff, sped-up farm work and replaced the fittest horses which had been enlisted alongside the men. ${ }^{128}$ The decision not to purchase the tractor may have been one of finance: in the farm bailiff's view, the asylum had the philosophy of doing everything atleast expense, which probably adversely affected "the returns from the stock and the present condition of all the herds". ${ }^{129}$ Relentless economising and understaffing may also have been associated with lack of attention to the environment, probably linked to the death of one cow, found to have nails, wire, tin, stones and ashes in her stomach at post mortem. ${ }^{130}$

\section{FUEL}

Before the war, in most asylums, coal provided heating and was used to generate gas and electricity for domestic amenities and for light industry in the workshops. The Board was impressed with one asylum which generated its own electricity for lighting and recycled the steam to supply the entire asylum with hot water, ${ }^{131}$ and another which reduced its coal consumption by lubricating the electricity-generating steam-engines with graphite rather than oil, which allowed vast quantities of water, previously wasted due to oil contamination, to be re-used in the boilers. ${ }^{132}$ Praise for these innovations was aligned with achieving budgetary targets. ${ }^{133}$

Coal shortages started at the beginning of the war, "with the Railways under the control of the Government, and the first necessity being the safety of the Nation", ${ }^{134}$ leading to additional reasons for fuel economy, both for private households and public institutions. ${ }^{135}$ One way in which the authorities tried to prevent "fuel fraud" and inequity, was to allow each household to register with only one coal merchant. ${ }^{136}$ However, in asylums, as with food, the coal was pooled which facilitated inequitable distribution. One medical superintendent, for example, received a coal allowance for his "motor garage". ${ }^{137}$ By contrast, the VC at Hanwell reprimanded a nurse for unnecessary use of gas when she was caught frying onions late at night over the gas in her bedroom. She justified her cooking as not wasting gas, because after dark she needed a light anyway 
and the gas served both purposes simultaneously. The same asylum used gas to make tea for working women patients when they returned to the ward in the afternoon. The VC wanted to discontinue this practice, but the medical superintendent refused to allow them to do so, since "it would do away with perhaps the last pleasure and privilege" left to those patients, which could only be "justified in case of grave necessity". ${ }^{138}$

Fuel supplies became dangerously depleted, but not quite "grave". Six months into the war, in mid-winter, the LCC asylums at Banstead and Long Grove had only 4 days' coal in stock. Claybury had sufficient for one week, and the others had marginally more. Military demands for coal, plus reduced labour and flooding in the mines, hindered collieries from filling the LCC's coal order. Lack of equipment to unload coal from boats on the Thames, plus "congestion on the railways" delayed deliveries. ${ }^{139}$ Hanwell had a slight advantage over the other asylums: its coal was delivered by barge as it had its own dock on the Grand Union Canal which ran along its southern perimeter. To monitor coal deliveries, each asylum had a weighbridge. Sometimes asylums received under-deliveries, and very occasionally, slight excess. ${ }^{140}$ The variability might have been due to deliberate under-supply or genuine error, due to faulty weighbridges at collieries or trucks being filled with wet coal which then dried. ${ }^{141}$ Large deficits in the region of 2 tons were harder to explain and asylums sought answers or refunds from their suppliers. ${ }^{142}$ With rising fuel prices, careful tendering was needed for contracts on huge purchases for institutions, such as for an order of over 6000 tons of "house coal" to provide ward heating for six months in the LCC asylums. ${ }^{143}$

Late in 1915, the LCC advised its asylums that infirmary wards could be heated at night, but other wards should be heated only if temperatures fell below freezing, ${ }^{144}$ hardly likely to promote a good night's sleep for patients or provide a healthy work environment for night staff. When the Board inspected Claybury in 1916, and patients complained about intense cold, it advised more heating, ${ }^{145}$ but conflicting advice from higher authorities hardly helped VCs steer a safe course. The Household Coal Distribution Order 1917 prompted the LCC to state that:

consumption of coal and coke at the London County Asylums has always been closely studied, and that the quantities consumed have been brought to what is believed to be the lowest level which is compatible with the efficiency of the administration of the asylums and the health of the inmates. ${ }^{146}$ 
It is unclear who, if anyone, defined "compatible...with health" or what it meant in practice. Using the outdated derogatory term "inmates", rather than the more respectful "patients" which was usually found in official asylum documents at this time, suggested negativity towards those in their care, which may have reflected on decisions regarding distribution of precious resources.

In autumn 1918, because of the cold, Claybury's VC predicted increasing death rates, which were already well above those in the community and in most other asylums. The LCC could envisage no way to prevent them. ${ }^{147}$ By closing some wards for the winter to help economise on fuel, ${ }^{148}$ other wards became unhealthily overcrowded, creating environments ripe for spreading infectious diseases. The authorities were under pressure to conform to fuel economy targets, and compared to the other LCC asylums, Claybury used more than its expected share, attributed to its damp location on London clay soil. ${ }^{149}$ However, both the LCC and Claybury's VC were complacent about the risks of their austerity measures. As with food, the authorities tended to accept their allocations of fuel without demanding more, even when human tragedy was predicted.

\section{CONCLUSIONS}

John Walton wrote in his book on fish and chips that, in 1910, the eminent Scottish psychiatrist Sir James Crichton Brown praised the warming, sustaining and nourishing benefits of fish and chips, which might also be "a useful auxiliary in the fight against tuberculosis". 150 Walton commented that "Perceptions of living standards were as important as actual nutritional levels", and that the warmth, tastiness and timesaving qualities of fish and chips for the general population was an argument for eating it during the war. ${ }^{151}$ Fish and chips would have had value against tuberculosis in the general sense of being nutritious, high in calories and protein, but no asylum menus have come to light which included it, despite the country being self-sufficient for fish and potatoes.

Aiming to feed the patients and resident staff and keep them warm was an enormous juggling act with moving goal posts to conform to restrictions and to ensure best use of erratic supplies with lowest expenditure. The asylum leadership obeyed directives, enforced national guidelines, and accepted negative outcomes-including a high death rate-as inevitable. Strictly obeying orders given by superiors effectively 
displaced responsibility and accountability for adverse consequences from any one level of staff or leadership onto someone higher in the chain. The authoritarian management system may have inhibited lateral thinking, innovation and communication to find solutions, such as by consulting or working collaboratively with the prison service to overcome shared challenges. The rigidity of management was compatible with Erving Goffman's administrative structure of a "total institution", 152 but it contrasted with government tactics at the time, demonstrated in its initial attempts to involve the public in the war effort voluntarily rather than through compulsion.

Whether due to lack of scientific and nutritional knowledge, or deliberately disregarding it, the leadership demonstrated little awareness of potential interactions between diet, cold and illness. Some doctors opposed the decisions of VCs, or at least warned of the consequences, regarding reducing patients' food intake. Occasionally the doctors requested more food for patients, but most remedial action concerning food and warmth was minimal and sluggish at best. Potential adverse consequences were rarely used as a basis for arguing for more by VCs or the Board, but the supposition that no more would be provided was hardly an ethical reason for not asking for it. It is also hard to justify why ward staff were allowed to neglect the simple, cheap and valuable practice of weighing patients to detect malnutrition and chronic disease. Overall, these findings suggest a lack of care rather than just a lack of resources.

Frugality towards patients and obsequiousness to seniors were parts of asylum culture, and institutional culture was (and is) notoriously hard to change. The culture of an acceptable way to care for patients established before the war did not adapt in a humane manner to the extreme challenges of wartime. The hierarchical structure of the asylums created a discriminatory scenario when considering basic needs such as food and warmth. Senior staff, particularly medical superintendents, received excessive life-style privileges. This demonstrated to other staff that it was acceptable for those with greater authority to consume more than those lower in the pecking order. It may therefore have encouraged and perpetuated staff taking food intended for patients. Social class inequality was not unique to asylums, but hierarchical food provision, which was detrimental to patients, was a potentially avoidable situation. ${ }^{153}$ The authorities, however, could justify prioritising the needs of staff by arguing 
that the fragile asylum care system risked disintegration if they did not. They had no such incentive for patients.

The war time supply chain and distribution of food and fuel in the asylums is a study of the effects of austerity, rigid rules and questionable management methods by the authorities, concerning the lives of mentally unwell people. A Times leader in 1919 about the asylums asked: "Have we been sending some of our lunatics into the Army and starving the others?" It called the Board to account. ${ }^{154}$

\section{Notes}

1. Napsbury H50/A/01/022 Meeting, 6 August 1914, 167-72 LMA.

2. Tenna Jensen, "The Importance of Age Perceptions and Nutritional Science to Early Twentieth-Century Institutional Diets," Social History of Medicine 30 (2017): 158-174, 171; LCC LCC/MIN/00581 Meeting, 21 December 1915, 260-62 LMA.

3. James Thomson, The Works of James Thomson: With His Last Corrections and Improvements ... To Which Is Prefixed, the Life of the Author, by Patrick Murdoch (London: J Rivington, 1788).

4. Gerd Hardach, The First World War, 1914-1918 (tr. Peter and Betty Ross) (London: Allen Lane, 1977), 112; Derek Oddy, From Plain Fare to Fusion Food: British Diet from the 1890s to the 1990s (Suffolk: Boydell Press, 2003), 71.

5. Ian Beckett, Home Front 1914-18: How Britain Survived the Great War (Richmond: The National Archives, 2006), 107-8.

6. Oddy, From Plain Fare, 71.

7. William Beveridge, British Food Control (London: Oxford University Press, 1928), 1.

8. Beveridge, Food Control, 6.

9. Hardach, First World War, 127.

10. Beveridge, Food Control, 1.

11. Hardach, First World War, 124.

12. Hardach, First World War, 130.

13. Working Class Cost of Living Committee, Report of the Committee Appointed to Enquire Into and Report Upon (i) The Actual Increase Since June 1914, in the Cost of Living to the Working Classes and (ii) Any Counterbalancing Factors (Apart from Increases in Wages) Which May Have Arisen Under War Conditions Cd. 8980 (Sumner Committee) (London: HMSO, 1918); Ian Gazeley and Andrew Newell, "The First World War and Working-Class Food Consumption in Britain," European Review of Economic History 17 (2013): 71-94. 
14. Beckett, Home Front, 110.

15. Richard van Emden and Steve Humphries, All Quiet on the Home Front: An Oral History of Life in Britain During the First World War (London: Headline, 2003), 199.

16. Beveridge, Food Control, 19.

17. Beveridge, Food Control, 20.

18. Lunacy Act 1890 section 283.

19. Beveridge, Food Control, 2.

20. Oddy, From Plain Fare, 78.

21. Oddy, From Plain Fare, 72.

22. Director of the Horticultural Section of the Food Production Department of the Board of Agriculture, BoC W/FM, 21 March 1917, 98 MH 50/45 TNA.

23. Beveridge, Food Control, 1.

24. Jeremy Paxman, Great Britain's Great War (London: Penguin, 2013), 216.

25. Beveridge, Food Control, 217.

26. Beveridge, Food Control, 206-7.

27. Beveridge, Food Control, 221.

28. Beveridge, Food Control, 233.

29. LCC LCC/MIN/00580 Meeting, 6 January 1915, 163-64; Claybury LCC/MIN/00947 Meeting, 2 March 1916, 172; Claybury LCC/MIN/00948 Meeting, 15 March 1917, 54 LMA.

30. Rules made by the Commissioners in Lunacy 1907-1929, MH 51/682 TNA.

31. Claybury LCC/MIN/00948 Meeting, 21 June 1917, 201 LMA.

32. Claybury LCC/MIN/00949 Meeting, 23 May 1918, 78 LMA.

33. Committee on the Administration of Public Mental Hospitals (Chairman: Sir Cyril Cobb) (Cobb Inquiry), 24 February 1922 Dr. Perceval Q:426-32, MH 58/219 TNA; Ministry of Health $(\mathrm{MoH})$, Report of the Departmental Committee on the Administration of Public Mental Hospitals Cmd. 1730 (London: HMSO, 1922).

34. Beveridge, Food Control, 329; Major Greenwood and Cecily Thompson, "An Epidemiological Study of the Food Problem," Proceedings of the Royal Society of Medicine 11 (1918) (Section on Epidemiology and State Medicine): 61-84, 65.

35. Benjamin Seebohm Rowntree, Poverty: A Study of Town Life (London: Macmillan, 1902), 234, 235, 239.

36. Diane Carpenter, "'Above All a Patient Should Never Be Terrified': An Examination of Mental Health Care and Treatment in Hampshire 1845-1914" (PhD thesis, University of Portsmouth, 2010), https://researchportal.port.ac.uk/portal/files/5877161/Diane_ Carpenter_PhD_Thesis_2010.pdf, 166. 
37. LCC LCC/MIN/00583 Meeting, 30 April 1918, 534 LMA.

38. Robert Armstrong-Jones, "Mortality Among Lunatics," Times, 10 September 1919.

39. William Stoddart, Mental Nursing (London: Scientific Press, 1916), 72.

40. Cobb Inquiry, 15 March 1922 Mr. Sale Q:700, MH 58/219 TNA.

41. Cobb Inquiry, 30 March 1922 Edward Mason Q:2130, MH 58/220 TNA.

42. LCC LCC/MIN/00583 Meeting, 24 July 1917, 14 LMA.

43. Hanwell LCC/MIN/01097 Meeting, 24 September 1917, 181-83 LMA.

44. LCC LCC/MIN/00580 Meeting, 27 July 1915, 695 LMA.

45. Claybury LCC/MIN/00949 Meeting, 23 May 1918, 66 LMA.

46. LCC LCC/MIN/00582 Meeting, 27 February 1917, 441 LMA.

47. Beveridge, Food Control, 222.

48. LCC LCC/MIN/00580 Meeting, 27 July 1915, 694 LMA.

49. Cobb Inquiry, 11 April 1922 Rev WD Yoward (VC chairman) Q:309298, 3048-50, MH 58/220 TNA.

50. BoC, letter to MSs, 2 March 1917 MH 51/239 TNA; LCC LCC/MIN/00583 Meeting, 29 January 1918, 283 LMA.

51. BoC, letter to MSs, 19 January $1918 \mathrm{MH} \mathrm{51/239}$ TNA.

52. LCC LCC/MIN/00583 Meeting, 26 March 1918, 436 LMA.

53. Van Emden and Humphries, All Quiet, 196.

54. LCC/MIN/00759 Presented papers of sub-committee 1909-1923, Summaries of replies from asylums, 2 November 1915 LMA.

55. Van Emden and Humphries, All Quiet, 196.

56. Ministry of Food (Fish Section), "Pickled Herrings," September 1917, MH 51/239 TNA.

57. Montagu Lomax, The Experiences of an Asylum Doctor (London: Allen and Unwin, 1921), 127; John Crammer, "Extraordinary Deaths of Asylum Inpatients During the 1914-1918 War," Medical History 36 (1992): 430-41, 439, citing Annual Reports of the Commissioners in Lunacy, 1908, 1911.

58. BoC, letter to MSs, 2 March 1917 MH 51/239 TNA; LCC/MIN/00759 Presented papers of sub-committee 19091923 Suggested further economies 4 August 1915; Claybury LCC/MIN/00947 Meeting, 2 March 1916, 62; Hanwell LCC/MIN/01094 Meeting, 17 August 1914, 40 LMA.

59. Jensen, "Early Twentieth-Century Institutional Diets": 164, 166.

60. WD Halliburton, "Cooking and Vitamins," Lancet 28 March 1914, 931-32.

61. Robert Branthwaite, Some Observations on the Prevalence of Tuberculosis, Dysentery, and "Severe Diarrhoea" in Mental Hospitals (London: HMSO, 1923), 8. 
62. Charles Mercier, "Diet as a Factor in the Causation of Mental Disease," Journal of Mental Science (JMS) 62 (1916): 505-29, 507.

63. Colney Hatch LCC/MIN/01001 Meeting, 6 June 1913, 111 LMA.

64. LCC LCC/MIN/00581 Meeting, 30 May 1916, 590 LMA.

65. Cobb Inquiry, "Reports of Visits to Mental Institutions: Dietary at Powick," 1922, MH 58/221 TNA.

66. LCC LCC/MIN/00582 Meeting, 25 July 1916, 33 LMA.

67. LCC LCC/MIN/00582 Meeting, 1 August 1916, 76-77 LMA.

68. BoC, letter to MSs, 13 February 1917, MH 51/239 TNA.

69. Oddy, From Plain Fare, 84.

70. Claybury LCC/MIN/00946 Meeting, 8 July 1915, 180 LMA.

71. Stoddart, Mental Nursing, 72.

72. LCC LCC/MIN/00580 Meeting, 27 July 1915, 699 LMA.

73. Hanwell LCC/MIN/01097 Meetings: 30 July 1917; 27 August 1917, 165 LMA.

74. Hanwell H11/HLL/B/35/006 Patients' records: male deaths 19361937 LMA.

75. Mary Riggall, Reminiscences of a Stay in a Mental Hospital (London: Arthur Stockwell, 1929), 5.

76. LCC LCC/MIN/00581 Meeting, 30 November 1915, 160 LMA.

77. Hanwell LCC/MIN/01098 Meeting, 23 September 1918, 140 LMA.

78. Claybury LCC/MIN/00949 Meeting, 23 May 1918, 71-72 LMA; Fourth Annual Report of the Board of Control, for the Year 1917 (London: HMSO, 1918), 23.

79. Hanwell LCC/MIN/01097 Meeting, 11 March 1918, 323 LMA.

80. Hanwell LCC/MIN/01098 Meeting, 6 May 1918, 40; 3 June 1918, 61 LMA.

81. Hanwell LCC/MIN/01098 Meeting, l July 1918, 77, 86 LMA.

82. BoC, circular to superintendents, "Food Allowances," 23 July $1918 \mathrm{MH}$ $51 / 239$ TNA.

83. LCC LCC/MIN/00584 Meeting, 25 February 1919, 305-6 LMA.

84. Napsbury H50/A/01/026 Meeting, 17 February 1916, 262 LMA.

85. BoC W/FM 3 October 1917, $279 \mathrm{MH} 50 / 45$ TNA.

86. Cobb Inquiry, 23 March 1922 JR Smith Q:1286, MH 58/219 TNA; $\mathrm{MoH}$, Committee on Administration.

87. BoC W/FM, 14 February 1917, 53 MH 50/45 TNA; Napsbury H50/A/01/026 Meeting, 13 February 1917, 261 LMA; LCC LCC/MIN/00582 Meeting, 27 February 1917, 438-39 LMA.

88. Prison dietary scales, Present and proposed diets, 9 March 1917 HO $45 / 14152$ TNA.

89. Charles Mercier, Lunatic Asylums, Their Organisation and Management (London: Griffin, 1894), 63. 
90. Hanwell H1l/HLL/A/14/003/012/001 Letter book, including inletters and copies of out-letters, statistics and other information 19151927, 25 February 1919, 61 LMA.

91. Colney Hatch LCC/MIN/01005 Meeting, 20 October 1916, 297-98 (Islington Daily Gazette, 15 October 1916) LMA.

92. First Annual Report of the Board of Control, for the Year 1914 (London: HMSO, 1916) (BoC AR 1914), Part 2, Glamorgan Asylum 4 November 1914, 229.

93. Claybury LCC/MIN/00948 Meeting, 8 November 1917. Between pp. 231-32, notes of conference on staff food, LMA.

94. BoC AR 1914, Part 2, Derbyshire Asylum 8 July 1914, 216.

95. Cobb Inquiry, 15 March 1922 AM Donaldson Q:619-21, MH 58/219 TNA.

96. Stoddart, Mental Nursing, 88.

97. Cobb Inquiry: 15 March 1922 Mr. Sale Q:700, MH 58/219; 30 March 1922 Edward Mason Q:2130, MH 58/220 TNA; Charles Mercier, The Attendant's Companion: A Manual of the Duties of Attendants in Lunatic Asylums (London: J and A Churchill, 1898), 4l; Stoddart, Mental Nursing, 88.

98. William Julius Mickle, General Paralysis of the Insane (London: HK Lewis, 1886), 84.

99. Mercier, Attendant's Companion, 41; Colney Hatch $\mathrm{H} 12 / \mathrm{CH} / \mathrm{A} / 08 / 001$ Reports to sub-committee, 25 January 1918, 12 LMA.

100. BoC AR 1914, Part 2, Brighton Asylum 27 March 1914, 345.

101. BoC AR 1914, Part 2, Nottingham City Asylum 29 January 1914, 370.

102. BoC AR 1914, Part 2, Cambridge and Isle of Ely Asylum 21 October 1914, 202.

103. Colney Hatch LCC/MIN/01001 Meeting, 23 May 1913, 93 LMA.

104. LCC LCC/MIN/00583 Meeting, 24 July 1917, 26 LMA.

105. LCC/MIN/00759 Presented papers of sub-committee 1909-1923 Suggested further economies, 4 August 1915 LMA.

106. LCC LCC/MIN/00581 Meeting, 30 November 1915, 166 LMA; and LCC LCC/MIN/00584 Meeting, 26 November 1918, 109: for Christmas; patients, $9 \mathrm{~d}$ per head; staff $2 \mathrm{~s} 9 \mathrm{~d}$ per head.

107. LCC LCC/MIN/00581 Meeting, 25 January 1916, 300-1 LMA.

108. Claybury LCC/MIN/00948 Meeting, 21 June 1917, 158-59 LMA.

109. Lomax, Experiences, 131.

110. Lomax, Experiences, 18.

111. Lomax, Experiences, 123.

112. Claybury LCC/MIN/00949 Meeting, 18 July 1918, 129 LMA.

113. Colney Hatch LCC/MIN/01007 Meeting, 11 January 1918, 16 LMA; Hanwell LCC/MIN/01095 Meeting, 7 June 1915, 97 LMA. 
114. LCC LCC/MIN/00583 Meeting, 18 December 1917, 237 LMA.

115. Claybury LCC/MIN/00946 Meeting, 22 July 1915, 94 LMA.

116. van Emden and Humphries, All Quiet, 218.

117. Hanwell LCC/MIN/01096 Meeting, 5 June 1916, 85, 95-96 LMA.

118. Colney Hatch LCC/MIN/01001 Meetings: 25 April 1913, 53; 6 June 1913, 123 LMA.

119. Hanwell LCC/MIN/01094 Meetings, 26 October 1914, 113, 23 November 1914, 142, 1 February 1915, 219 LMA.

120. Hanwell LCC/MIN/01095 Meeting, 5 July 1915, 115 LMA.

121. Hanwell LCC/MIN/01096 Meeting, 27 March 1916, 19 LMA.

122. Hanwell LCC/MIN/01097 Meeting, 7 May 1917, 67 LMA.

123. Hanwell LCC/MIN/01098 Meeting, 29 July 1918, 107 LMA.

124. Bonnie White, "Feeding the War Effort: Agricultural Experiences in First World War Devon, 1914-17," Agricultural History Review 58 (2010): 95-112, 99; LCC LCC/MIN/00581 Meeting, 30 May 1916, 602 LMA.

125. White, "Feeding the War Effort".

126. Hanwell LCC/MIN/01096 Meeting, 20 November 1916, 241 LMA.

127. Anon. "Happenings," United Methodist, 7 February 1918, 62; Beckett, Home Front, 113.

128. Eric Pryor, Claybury 1893-1993: A Century of Caring (London: Forest Healthcare, 1993), 62.

129. Hanwell LCC/MIN/01096 Meeting, 27 March 1916, 20 LMA.

130. Hanwell LCC/MIN/01094 Meeting, l February 1915, 230 LMA.

131. BoC AR 1914, Part 2, 309-10.

132. Anon. "Asylum Reports: London County Council, 1914," JMS 62 (1916): 627-34, 631.

133. Lomax, Experiences, 123.

134. Napsbury H50/A/01/022 Meeting, 6 August 1914, 167-72 LMA.

135. LCC LCC/MIN/00581 Meeting, 18 April 1916, 523 LMA.

136. Beveridge, Food Control, 228.

137. LCC LCC/MIN/00583 Meeting, 27 November 1917, 181 LMA.

138. Hanwell LCC/MIN/01098 Meeting, 3 June 1918, 60; 26 August 1918, 127 LMA.

139. LCC LCC/MIN/00580 Meetings: 26 January 1915, 182, 23 February 1915, 263; 23 March 1915, 369 LMA.

140. Hanwell LCC/MIN/01094 Meeting, 15 February 1915, 250 LMA.

141. Colney Hatch LCC/MIN/01005 Meeting, 28 January 1916, 61 LMA.

142. Colney Hatch LCC/MIN/01003 Meeting, 25 September 1914, 105 LMA.

143. LCC LCC/MIN/00580 Meeting, 23 March 1915, 369 LMA; LCC LCC/MIN/00581 Meeting, 26 October 1915, 23-24 LMA. 
144. LCC/MIN/00759 Presented papers of sub-committee 1909-1923, letter LCC to MSs, 5 November 1915 LMA.

145. Claybury LCC/MIN/00947 Meeting, 23 November 1916, between pp. 273-74 report on BoC visit, 17 November 1916 LMA.

146. LCC LCC/MIN/00583 Meeting, 30 October 1917, 143 LMA.

147. Claybury LCC/MIN/00949 Meeting, 12 September 1918, 169 LMA; LCC LCC/MIN/00584 Meeting, 29 October 1918, 25 LMA.

148. Colney Hatch $\mathrm{HI} 2 / \mathrm{CH} / \mathrm{A} / 08 / 001$ Reports to sub-committee, 1 November 1918, 107 LMA.

149. Claybury LCC/MIN/00947 Meeting, 11 May 1916, 104 LMA.

150. John Walton, Fish and Chips, and the British Working Class, 1870-1940 (London: Leicester University Press, 2000), 13.

151. Walton, Fish and Chips, 18.

152. Erving Goffman, Asylums: Essays on the Social Situation of Mental Patients and other Inmates (1961; Harmondsworth: Penguin, 1980).

153. Carpenter, "Above All," 144: meat ration per week: male patients, $30 \mathrm{oz}$ $\left(0.85 \mathrm{~kg}\right.$, uncooked); female staff $5^{1 / 4} \mathrm{lbs}(2.4 \mathrm{~kg})$; male staff $7 \mathrm{lbs}$ $(3.2 \mathrm{~kg})$.

154. Anon. "Lunacy During the War," Times, 6 September 1919.

Open Access This chapter is licensed under the terms of the Creative Commons Attribution 4.0 International License (http://creativecommons.org/licenses/ by $/ 4.0 /)$, which permits use, sharing, adaptation, distribution and reproduction in any medium or format, as long as you give appropriate credit to the original author(s) and the source, provide a link to the Creative Commons license and indicate if changes were made.

The images or other third party material in this chapter are included in the chapter's Creative Commons license, unless indicated otherwise in a credit line to the material. If material is not included in the chapter's Creative Commons license and your intended use is not permitted by statutory regulation or exceeds the permitted use, you will need to obtain permission directly from the copyright holder.

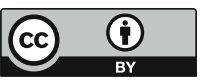

